\title{
PV System fed Closed Loop Control of Switched Reluctance Motor using Zeta Converter
}

\author{
Pradeep Shankar ${ }^{1}$ | Dr.S.Chitra ${ }^{2}$
}

${ }^{1}$ PG Scholar, Department of EEE, Government College of Technology, Coimbatore, Tamil Nadu, India.

${ }^{2}$ Assistant Professor,Department of EEE, Government College of Technology, Coimbatore, Tamil Nadu, India.

\section{To Cite this Article}

Pradeep Shankar and Dr.S.Chitra, "PV System fed Closed Loop Control of Switched Reluctance Motor using Zeta Converter", International Journal for Modern Trends in Science and Technology, 6(8): 125-128, 2020.

Article Info

Received on 21-June-2020, Revised on 15-July-2020, Accepted on 29-July-2020, Published on 07-August-2020.

\section{ABSTRACT}

The utilization of DC power obtained from Photovoltaic panels are more reliable and economical. The usage of PV fed Motor drives increases the demand in domestic, agricultural and industrial appliances. The objective of the proposed method is to control the speed of the 6/4 pole SRM motor in a closed-loop system using PI controller by employing the zeta converter. The velocity versus the position of the translator is being controlled with the PI controller. The control system maintains the desired speed in variations of the load or the motor parameters, by selecting predetermined switching angles. The performance of the SRM motor has been analyzed through MATLAB/Simulink platform and results show the effectiveness of the proposed system.

KEYWORDS: Switched reluctance motor, SRM control, Speed control, ZETA Converter

\section{INTRODUCTION}

Electrical drives play an important role in modern industries, the use of PV systems as a power source for electrical machines are considered a promising area in PV applications due to the ongoing growth of PV-market. PV-powered SRM motors at different solar intensities, different loading conditions have been proposed. In this study, PV arrays are designed to provide their maximum power at the rated conditions of the SRM when the PV array is fully illuminated.

Switched Reluctance Motors (SRM) are relatively new additions to a group of well-established variable speed electric motors. The major difference that distinguishes them from other conventional drive is simple, low cost, and rugged constructions. It converts the reluctance torque into mechanical power. In the SRM both the stator and rotor have the salient-pole, which contributes to producing a high output torque. Thus the SRM motor has various benefits compared to other motors this project is an attempt to use SRM motor in various applications like water pump, washing machine, etc.., by controlling its speed.

\section{Proposed System}

The block diagram of the proposed system is shown in Fig 1.1 consists of power supply from PV panels, Motor driver, SRM motor, Rotor position sensor (RPS) and zeta converter. The position of the rotor is being sensed by the rotor position sensor and it provides its corresponding output to its error detector. Error detector compares the reference speed with the actual speed to provide error signal which is given to the controller block. The PI controller gives the control signal to the converter as per the error signal. The speed of the motor is being controlled by the converter through proper 
excitation of their corresponding windings. PV array is used as a source from which maximum power is obtained from the MPPT algorithm.

The DC-DC converter is used to convert the variable dc to fixed dc voltage. Which is fed to the motor driver, were the gate pulses are controlled by the rotor position sensor. By triggering the motor drivers the pulse is fed to the stator windings which tend to align the rotor to its corresponding phases.

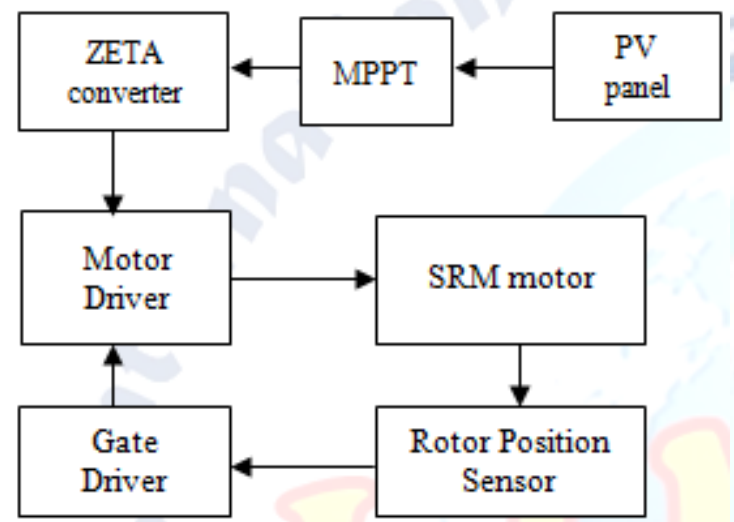

Fig 1.1 Block Diagram of Speed control of SRM.

\section{ZETA CONVERTER}

Power converters play a main role in the process, which is the heart of the entire system. It is installed between the source and load. In this paper, zeta converter has been chosen as a proposed converter, because of the advantages like low settling time, adaptability.

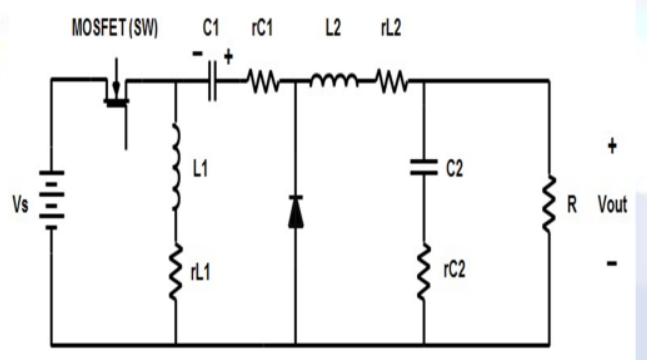

Fig 1.2 Zeta converter.

Zeta converter is a fourth-order Nonlinear DC-DC converter presented here, in Fig 1.2, has two inductors, two capacitors each with an Equivalent Series Resistance, and a diode. The Zeta converter can operate in step up or step down modes to supply a load. The input to the Zeta converter is a DC voltage, which can be obtained from solar arrays and in this case, DC-DC Zeta converter which converts this low-level DC input to a highlevel DC output voltage. MOSFET is used as an operating switch which connects (ON) or disconnects $(\mathrm{OFF})$ the $\mathrm{DC}$ voltage source to or from the circuit.

\section{OPERATION OF ZETA CONVERTER}

The Zeta converter circuit has two circuit states formed by the MOSFET switch. The first state is when the MOSFET switch is ON as shown in Fig 1.3, the diode is reversed biased, and thus the diode will act as an open circuit below. In this state, the inductors L1 and L2 are charging, and the inductors currents are increasing linearly. Capacitors $\mathrm{C} 1$ and $\mathrm{C} 2$ which is the output part respectively and the inductors currents are decreasing linearly.

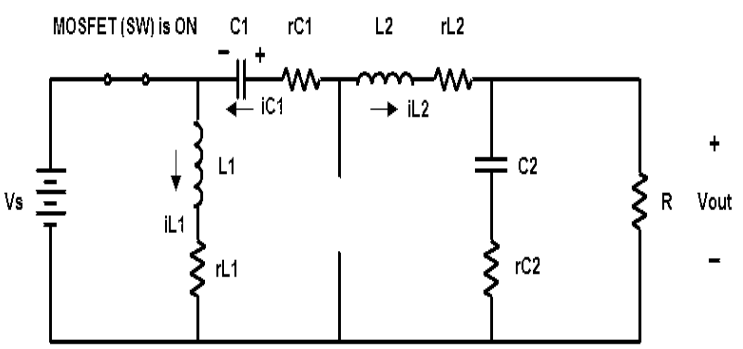

Fig 1.3 Equivalent Zeta converter circuit when the switch is ON.

The Second state is when the MOSFET switch is OFF as shown in Fig 1.4 below, the diode is forward biased, thus, the diode will act as a short circuit. In this state, the inductors discharging, and the energies in L1 and L2 are discharged to capacitors $\mathrm{C} 1$ and $\mathrm{C} 2$ which is the output part respectively and the inductors currents are decreasing linearly.

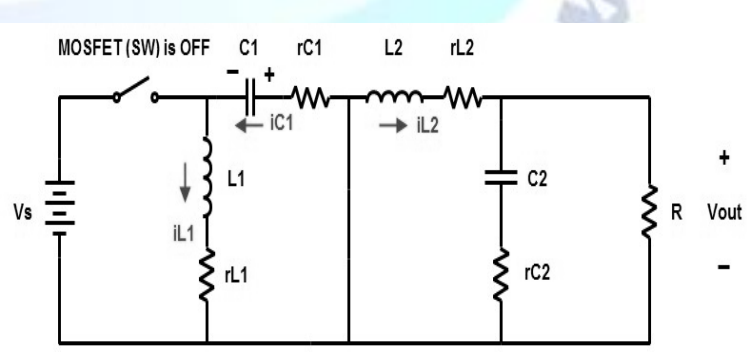

Fig 1.4 Equivalent Zeta converter circuit when the switch is OFF.

\section{MPPT ALGORITHMS}

MPPT algorithms are necessary for PV applications because the maximum power of a solar panel varies with the irradiation and temperature, so the use of MPPT algorithms is required to obtain the maximum power from a 
solar array. Among these techniques, the $\mathrm{P} \& \mathrm{O}$ algorithms are the most common. These techniques have the advantage of easy implementation. Other techniques based on different principles are fuzzy logic control, neural network, fractional open-circuit voltage or short circuit current, etc.

\section{RESULTS AND DISCUSSIONS}

In the Simulink of SRM drive model is shown in Fig 1.5 , the rotor position sensor gives the information about the rotor concerning the reference axis to the PI controller. The controller also receives the status of actual speed, flow through the motor. The controller compares the signals obtained from the rotor position sensor and reference and generate square pulses to the power semiconductor devices connected to the SRM motor. This signal is fed to the motor controller.

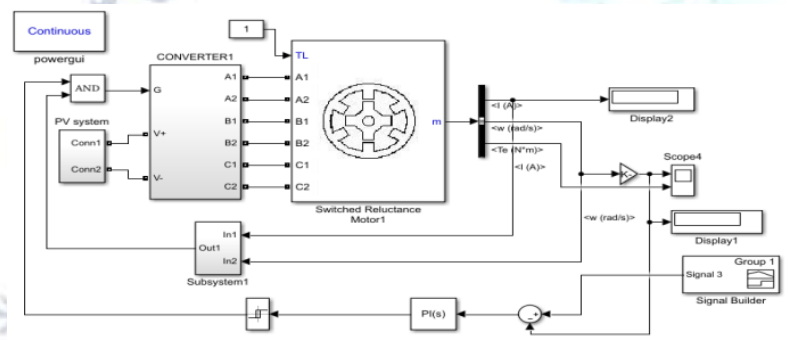

Fig 1.5 Simulink model of the proposed system.

The phase winding of the SRM is energized depending upon the turning on and off of the power semiconductor switching circuit.

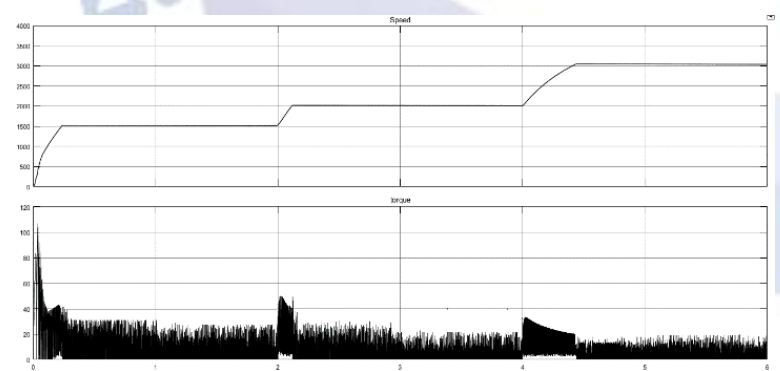

Fig 1.6 speed vs torque output.

The Simulink model is designed for the speed control of switched reluctance motor using the PI controller and their corresponding output speed vs torque waveform is shown in Fig 1.6. If variable set speed is given by using signal builder block as shown in Fig 1.7, constant speed is obtained on the output and their respective torque also obtained, the settling time of different speed are in ranges between 0.2-0.5 seconds.

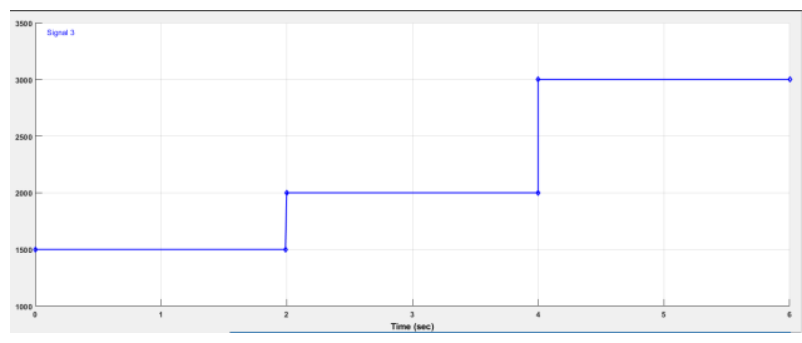

Fig 1.7 set speed at signal builder block.

The set speed reference which is given as the input to the controller is shown. The values are listed in table 1.1 as

Table 1.1 set speed values for different time ranges

\begin{tabular}{|c|c|}
\hline TIME(S) & SPEED $(\mathrm{rpm})$ \\
\hline $0-2$ & $1500 \mathrm{rpm}$ \\
\hline $2-4$ & $2000 \mathrm{rpm}$ \\
\hline $4-6$ & $3000 \mathrm{rpm}$ \\
\hline
\end{tabular}

The input from the PV is fed to the power converters which is used to convert one level of dc voltage to another level either by step up or step-down. The Zeta converter is used to step-up voltage from Photovoltaic (PV) array which is shown in Fig 1.8. And the comparison between the input voltage from the PV and output voltage of the converter is shown in Fig 1.9.

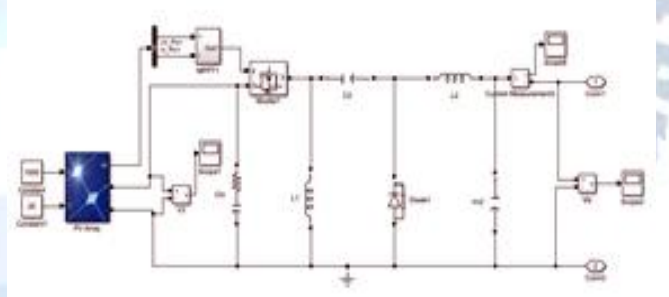

Fig 1.8 Simulink model of ZETA converter.

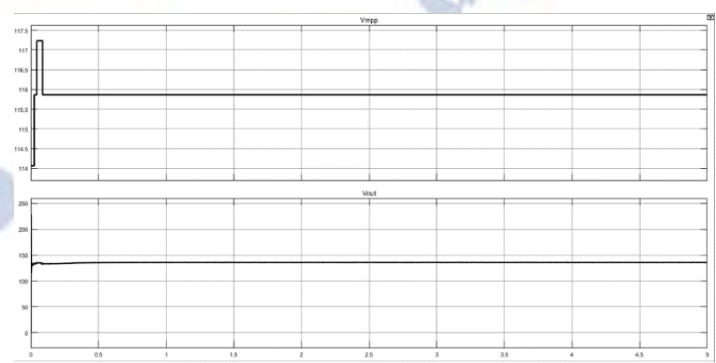

Fig 1.9 PV input \& converter output voltage.

A control technique is required to get the appropriate duty ratio of the gate pulse for the switch of the Zeta converter and also to achieve the Maximum Power Point (MPP). The Perturb and 
observe $(\mathrm{P} \& \mathrm{O})$ technique is used due to its simplicity and its quick response to achieve the MPP and generate control pulses to the power semiconductor switching circuits which are shown in Fig 1.10.

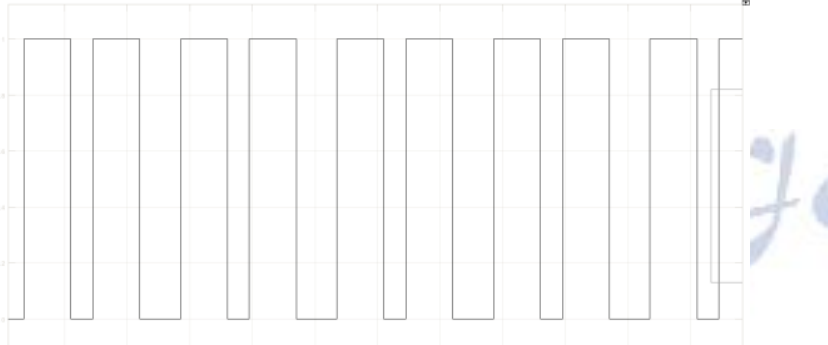

Fig 1.10 PWM pulse generated by MPPT.

Different types of power semiconductor switching circuits are used for different application. Normally the circuits are inverter circuit configuration. The power semiconductor devices are turned on and off by controller circuit.

This control system consists of a power semiconductor switching circuit, SRM with a rotor position sensor and feedback system. In this system feedback signal from the rotor position system acts as a controller for the switched reluctance motor.

The closed-loop control of SRM can perform the following functions

a) Control the feedback loops.

b) PWM or square wave signal generation to inverters.

c) General sequencing control.

\section{Conclusion}

Switched reluctance motor drive is more efficient and practical solution for constant load driving system. The SRM drives have the significant of having high starting torque without the problem of excessive inrush current due to self -inductance. The SRM is designed with low rotor inertia and high torque inertia ratio.

The drive system of the proposed SRM is used as closed-loop control. So the required speed level achieved by using an asymmetric converter. The proposed system is used for all types of electric vehicle and industrial applications. The performance of the SRM drive is simulated with MATLAB Simulink. Thus the speed of SRM drive is controlled.

\section{REFERENCES}

[1] Anjanee Kumar Mishra, Bhim Singh, "Design of solar-powered agriculture pump using new configuration of dual-output buck-boost converter", IET Renew. Power Gener, 2018, Vol. 12 Iss. 14, pp. 1640-1650.

[2] Vijay Babu Koreboina , B. L. Narasimharaju, D. M. Vinod Kumar, "Performance investigation of simplified PWM MPPT approach for direct PV-fed switched reluctance motor in water pumping system", IET Electr. Power Appl. The Institution of Engineering and Technology 2017, ISSN 1751-8660.

[3] Anjanee Kumar Mishra, Bhim Singh, "Solar Photovoltaic Array Dependent Dual Output Converter Based Water Pumping Using Switched Reluctance Motor Drive", IEEE 2017.IEEE Transactions on Industry Applications.

[4] Hossein Rouhani, Rasoul Mohammadi Milasi and Caro Lucas, "Speed Control of SRM using Emotional Learning Based Adaptive Controller," International Conference on Control and Automation (ICCA2005) June 27-29, 2005.

[5] Bhim Singh, Anjanee Kumar Mishra, "SPV Array Powered SC Buck-Boost Converter Fed SRM Drive for Water Pumping", International Conference on Emerging Trends in Electrical, Electronics and Sustainable Energy Systems (ICETEESES-16).

[6] Alia M. Khatab, Mostafa, Marei, Hadi M. Elhelw, an Electric Vehicle Battery Charger Based on Zeta Converter Fed from a PV Array, 978-1-5386-5186-5/18/\$31.00 ( 2018 IEEE.

[7] M.Asgar, E.Afjei, A.Siadatan A.Behbahani, "A12/8 Double-Stator Switched Reluctance Motor for Washing Machine Application", the 6th International Power Electronics Drive Systems and Technologies Conference (PEDSTC2015) 3-4February 2015.

[8] Aman Jha and Bhim Singh, "Bridgeless ZETA PFC Converter for Low Voltage High Current LED Driver", 978-1-5090-4874-8/17/\$31.00 @2017 IEEE.

[9] M.Asgar1, E.Afjei, M.M.Mahmoodi, A.R.Bahrami, E.Z.Aliabadi, "A Double-Stator Switched Reluctance Motor for Direct-Drive Washing Machine Application,".

[10] Iqbal Husain, Senior Member, IEEE, and Syed A. Hossain, Member, IEEE, "Modeling, Simulation, and Control of Switched Reluctance Motor Drives," IEEE transactions on industrial electronics, December 2005.

[11] H.Parthsarathy, L.Udayakumar, Balasubramanian "Modeling and Simulation of PV Module and Zeta Converter" 2016 International Conference on Circuit, Power and Computing Technologies [ICCPCT]. 